\title{
PERCEPTION OF DIGITAL SURVEILLANCE: A COMPARATIVE STUDY OF HIGH SCHOOL STUDENTS IN THE U.S. AND CHINA
}

\author{
Benjamin Zhang, Topeka High School, bzhang99@sas.upenn.edu \\ Harry M. Peterson, Jr., Topeka High School, hpetersonjr@me.com \\ Wenying Sun, Washburn University,nan.sun@washburn.edu
}

\begin{abstract}
Digital surveillance is widely utilized around the world and has evoked increasingly controversial debates regarding its benefits and drawbacks. People in different countries may view surveillance differently due to cultural, political, and social elements. In addition, teenagers may have different views than adults concerning surveillance. In this research, we attempted to answer the following research question: "Do teenagers in different countries view digital surveillance differently?" We conducted a survey in US and Chinese high schools to answer this question. The survey results suggest there is not much difference between students' attitudes in the two countries, however, we identified significant differences in several accounts between students in public and private schools in each country. Research implications are discussed.
\end{abstract}

Keywords: Digital Surveillance, High School Students, Public School, Private School

\section{INTRODUCTION}

Surveillance is the act of monitoring behavior and activities for the purpose of influencing, managing, directing, or protecting people (Lyon, 2007). Digital surveillance is surveillance through the use of digital electronic devices such as cameras, computers, and other digital technologies. Digital, more specifically, refers to computerized technology (Merriam-Webster, n.d.). Digital methods tend to facilitate more pervasive surveillance in real time (Martin et al, 2009).

Digital surveillance has been widely utilized around the world. Cannataci, the first UN Privacy Chief, said: "If you look at CCTV alone, at least Winston [Winston Smith in Orwell's novel 1984] was able to go out in the countryside and go under a tree and expect there wouldn't be any screen, as it was called. Whereas today there are many parts of the English countryside where there are more cameras than George Orwell could ever have imagined." (Guardian, 2015). Countries like the U.S. and China are not far behind Great Britain. In Chinese cities, cameras are ubiquitous: along highways, in public parks, on rooftops and balconies, in elevators, in taxis, even in the stands at sporting events. According to a National Public Radio (NPR) report, China has become a surveillance state. In 2013, there were about 30 million cameras operating in China or about one for every forty three citizens, and camera sales were expected to grow 20 percent annually over the next five years (NPR, 2013). The US government has engaged in massive surveillance of millions of Americans. Evidence shows AT\&T made copies of emails, web browsing, and other Internet traffic to and from AT\&T customers and provided those copies to the National Security Agency (NSA). The data included Internet activities of AT\&T customers. As one expert observed, "this isn't a wiretap, it's a country-tap." (EFF, 2017).

The massive digital surveillance has attracted increasingly controversial debates regarding its benefits and drawbacks. Countries surveil for various reasons. However, many countries share the same underlying causes. People in different countries may view surveillance based on their own cultural, political, and social systems. In addition, adults and teenagers may have different views over surveillance, as they often do in many other issues. While adults may have a wider scope and a better understanding of the events around them, we limit the scope of this investigation to teenagers' views on the issue. These emerging adults will play a pivotal role in developing and shaping the society of the future, which makes it critically important to understand their perspectives on key social issues such as digital surveillance. 


\section{Issues in Information Systems \\ Volume 18, Issue 1, pp. 98-108, 2017}

In this research, we seek to answer the following question: "Do teenagers in different countries view digital surveillance differently?" We surveyed high school students in the U.S. and China to draw conclusions.

The rest of the paper is organized as follows. We first provide a literature review regarding survey reports on digital surveillance. We then present hypotheses and research methods for our studies. The results of the studies are presented next. Finally, we discuss results, research implications, and conclude with limitations and future work.

\section{LITERATURE REVIEW}

Literature on how people in different countries view digital surveillance is scarce. According to a BBC World Service survey of 17 countries, an average of 60 percent of respondents say they feel free from government surveillance in their country as opposed to the 36 percent who report not being free. Unlike the U.S. and Germany, all other surveyed countries have majorities who consider themselves free from government monitoring programs. In China, 76 percent say they feel free from government monitoring - the highest proportion in the survey. The survey includes 17,589 citizens across 17 countries between December 2013 and end of February 2014. The 17 countries surveyed are: Australia, Canada, China, France, Germany, India, Indonesia, Kenya, Mexico, Nigeria, Pakistan, Peru, Russia, South Korea, Spain, the UK, and the U.S.. In China, Indonesia, and Kenya, the samples are limited to major urban areas (Globe Scan, 2014).

We also identified a few articles pertaining to Americans' attitudes towards surveillance. A Gallup poll (Newport, 2013) reports 57 percent of Americans are concerned about their privacy rights being violated. However, more Americans disapprove (53\%) than approve (37\%) of the federal government agency program, which obtains records from US telephone and Internet companies to compile logs for telephone calls and Internet communications. Reasons for approving of the program include: it does not violate liberties; combatting terrorism is more important. Thirty percent disapprove of program even under some circumstances when it will be beneficial. Ten percent state they have no opinion.

According to a 2015 Pew research report (Rainie and Madden, 2015), 52 percent of Americans say they are "very concerned" or "somewhat concerned" about government surveillance of Americans' data and electronic communication. Men are more likely than women to say they are "very concerned" about government surveillance of Americans' data and electronic communications (21\% vs. $12 \%)$. Men are also more likely than women to be "very concerned" about surveillance over their own activities on mobile apps and search engines. Other findings include: Americans are comfortable targeting others for surveillance, but not themselves; a majority of Americans think monitoring is acceptable in certain instances as long as the targets are not average Americans. Americans age 50 and older are more likely than those in younger groups to say surveillance is acceptable across many of these specific scenarios.

Based on another Pew research report (Madden and Rainie, 2015), 88 percent say it is important they are not watched or listened to without their permission, and only a small minority says they are "very confident" the records obtained through surveillance will remain private and secure.

In summary, there is limited academic literature on peoples' perceptions on digital surveillance. We did not identify any literature noting how teenagers in different countries view digital surveillance.

\section{HYPOTHESES}

With crime and terrorism threats increasing around the world, questions of "who do we surveil" and "why do we surveil" keep comping up, prompting widespread discussions about the surveillance state's influence on race, the economy, security, and personal liberty (e.g. Ball and Snider, 2013; Markantonatou, 2007).

There have been conflicting views on digital surveillance. For example, former FBI Director Robert Mueller suggested NSA surveillance might have stopped 9/11 (CBSNews, 2013) while organizations such as Electronic 


\section{Issues in Information Systems \\ Volume 18, Issue 1, pp. 98-108, 2017}

Frontier Foundation devote themselves to exposing reports showing how NSA surveillance violates rights of the citizens. Generally, the commonly cited benefits of digital surveillance are: reducing crimes, improving public safety, and foiling terrorist attacks. The concerns of digital surveillance are: violating human rights and privacy, profiling or targeting certain religious or racial groups, data misuse and abuse, and inconveniencing daily activities.

How do students in China and the U.S. view digital surveillance differently? We derive our hypotheses based on each country's unique social, political, and educational underpinnings.

In China people live very close together. They are used to watching and being watched. Living space is crowded; people/neighbors know each other, hence, there is limited privacy.

Politically, China is ruled by an authoritarian central government with little participatory democracy. Decisions are made from top down; people have little say/involvement in decisions such as where and how much digital surveillance. Media serve as the mouthpiece of the government disseminating its propaganda. Dissent from the government is not well tolerated and can be quickly suppressed.

In the education system, the most academically able students attend the elite public schools, which are highly selective, admitting only those with the highest high-school entrance exam scores. Students, who were not admitted to the best public schools but are from affluent families, attend private high schools (Expat Arrivals, 2017). Private schools are gaining momentum, and a few have closed the academic performance gap with the elite public high schools.

The U.S., in contrast, is a free and democratic society with a strong participatory tradition. Liberty, privacy, and individual rights are highly valued and protected. Public schools are diverse racially and economically and socially liberal. The academic quality varies widely from district to district. Private schools are often either parochial or college preparatory. It is expensive, and the political environment tends to be less liberal than public schools.

Based on the above arguments, we hypothesize:

H1a: Chinese students will consent more to the benefits of digital surveillance than US students.

H1b: US students will be more concerned with the detrimental effects of digital surveillance than Chinese students.

H1c: Chinese students will view digital surveillance more favorably than US students.

H2a: In China, public school students will consent more to the benefits of digital surveillance than private school students.

$\mathrm{H} 2 \mathrm{~b}$ : In China, private school students will be more concerned about the detrimental effects of digital surveillance than public school students.

H2c: In China, public school students will view digital surveillance more favorably than private school students.

H3a: In the U.S., private school students will consent more to the benefits of digital surveillance than public school students.

H3b: In the U.S., public school students will be more concerned with the detrimental effects of digital surveillance than private school students.

H3c: In the U.S., private school students will view digital surveillance more favorably than public school students. 


\section{METHODOLOGY}

We chose four high schools for collection of data: two in China and two in the United States. The US high schools, one public and one private, are located in the Midwest. The public school has approximately 2,000 students comprised of all racial and social-economic backgrounds. The male vs female ratio is 48:52. The private school is a Catholic school with 500 students. The Chinese public high school is located in Southeast China and consists of 4,000 students. It is a highly selective school; only those with top high-school entrance exam scores are admitted. The male vs female ratio is 60:40. The Chinese private school has about 1,800 students with even gender distribution. Admission is not selective but students are from affluent families. Nearly all students in both Chinese schools are of the Han ethnic origin.

We created the survey using Survey Monkey. In both countries, we requested the collaborating teachers to share the survey link or paper copies of the survey from Survey Monkey with their colleagues to generate responses. The Chinese schools mainly used paper copies because students were not allowed to use electronic devices at school, and computer labs were not readily available. After the paper surveys were collected, data was entered on Survey Monkey. In the US high schools, we contacted teachers of mathematics, social sciences, humanities, and natural sciences, and requested them to share the survey link with their students.

In the survey, we asked six questions (B1-B6) on the pros of digital surveillance, ten questions (D1-D10) on the cons, and three questions (O1-O3) on general feelings of government digital surveillance. The scales for all questions are 1-7, 1 indicating strongly disagree, and 7 indicating strongly agree. The Chinese survey included both Chinese and English languages. All students in China have at least five years of English learning before they enter high school. We thought it was appropriate for them to see the English version along with the Chinese version.

\section{RESULTS}

In this section, we present results from Study 1 and Study 2. All analyses were done using SPSS Version 23.

\section{Study 1 - Survey}

Table 1 describes the demographics of the survey respondents. We received 204 complete survey responses from Chinese high schools: 107 are from public schools and 108 are from private schools. There are 215 responses from US high schools: 155 of them are from public schools and 49 from private schools. Among all respondents, 42.9 percent are male, 56.1 percent are female, and 1 percent are others.

Table 1. Respondents' Demographics

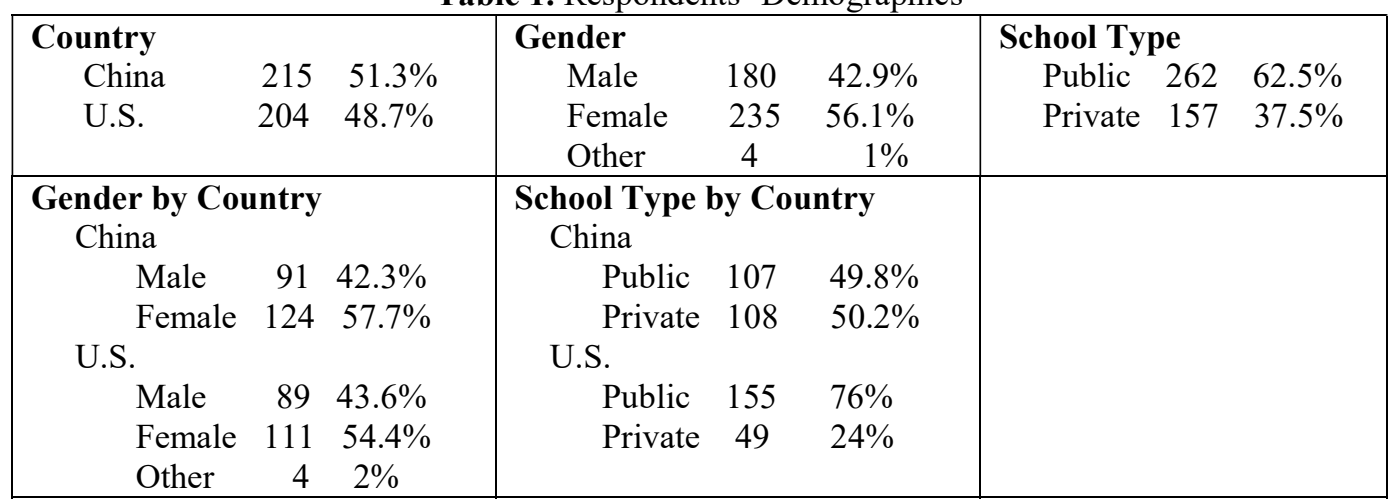

The means and standard errors of all responses are listed in Table 2. The scales for all questions are 1-7, 1 indicating strongly disagree, and 7 indicating strongly agree. B1, B2, and D7 have means 5.0 or above, suggesting respondents agree or strongly agree with those statements. B5, D1, D2, D3, D8, and O3 have means between 4.50 to 4.99 , suggesting the respondents somewhat agree with these statements. The respondents slightly agree with B4 and B6 


\section{Issues in Information Systems}

Volume 18, Issue 1, pp. 98-108, 2017

(4.20-4.49). Respondents slightly disagree with D4, D5, Q12, D9, D10, and O2 (3.80-3.97). O1 has a mean of 3.15 suggesting respondents generally do not approve of government surveillance.

Table 2. Overall Means

\begin{tabular}{|l|l|l|}
\hline$\#$ & Questions & Mean (SE) \\
\hline B1 & Digital surveillance helps reduce crimes. & $5.04(0.06)$ \\
\hline B2 & $\begin{array}{l}\text { Digital surveillance helps the police collect evidence to solve criminal } \\
\text { cases. }\end{array}$ & $5.84(0.05)$ \\
\hline B3 & Digital surveillance makes people feel safer. & $4.47(0.07)$ \\
\hline B4 & Digital surveillance improves public security. & $4.49(0.06)$ \\
\hline B5 & Digital surveillance helps foil terrorist attacks. & $4.52(0.08)$ \\
\hline B6 & Digital surveillance reduces corruption. & $4.27(0.07)$ \\
\hline D1 & Digital surveillance expands government power. & $4.77(0.07)$ \\
\hline D2 & $\begin{array}{l}\text { Digital surveillance infringes upon individual rights such as freedom of } \\
\text { action and speech. }\end{array}$ & $4.60(0.06)$ \\
\hline D3 & Digital surveillance invades privacy. & $4.79(0.06)$ \\
\hline D4 & Digital surveillance threatens democracy. & $3.88(0.07)$ \\
\hline D5 & Digital surveillance tends to target certain racial groups. & $3.91(0.08)$ \\
\hline D6 & Digital surveillance tends to target certain religious groups. & $3.84(0.07)$ \\
\hline D7 & Digital surveillance data can easily be abused. & $5.32(0.06)$ \\
\hline D8 & Digital surveillance data tends to be misused. & $4.94(0.06)$ \\
\hline D9 & Digital surveillance wastes tax payers' money. & $3.80(0.07)$ \\
\hline D10 & Digital surveillance inconveniences my daily actions. & $3.71(0.07)$ \\
\hline O1 & I approve of government surveillance. & $3.15(0.07)$ \\
\hline O2 & $\begin{array}{l}\text { I believe my government should substantially decrease digital surveillance } \\
\text { in my country. }\end{array}$ & $3.82(0.07)$ \\
\hline O3 & Overall, I believe digital surveillance is a good idea. & $4.54(0.07)$ \\
\hline
\end{tabular}

We compared the mean differences between responses from the two countries and tested whether the differences were statistically significant. The questions that showed statistically significant responses are: D1, D8, D10 (p-value $<=$ 0.05 ), and are bolded. The other differences are not statistically significant ( $\mathrm{p}$-value $>0.05$ ). Table 3 presents the means, mean difference, $t$-value, and p-value from each question. B1-6 are the benefits of digital surveillance. There is no significant difference on any of the six questions, therefore, H1 a is not supported. H1b is only partially supported. US students believed more strongly that digital surveillance expands government power than Chinese students (5.50 vs. 4.26, p-value $<0.001$ ). However, Chinese students believed data could be misused (5.22 vs. 4.64, p-value $<0.001$ ) and digital surveillance inconveniences daily actions $(4.10 \mathrm{vs.} 3.30$, p-value $<0.001)$ more so than US students. There are no significant differences on their general views of government surveillance (O1-O3, p-value $>0.40)$, therefore, $\mathrm{H} 1 \mathrm{c}$ is not supported. 
Table 3. U.S. Versus China

\begin{tabular}{|l|l|l|l|l|l|}
\hline Question & US & China & $\begin{array}{l}\text { Mean } \\
\text { difference }\end{array}$ & t-value & p-value \\
\hline B1 & $5.01(0.09)$ & $5.07(0.09)$ & -0.060 & -0.44 & 0.658 \\
\hline B2 & $5.72(0.08)$ & $5.92(0.08)$ & -0.196 & -1.65 & 0.100 \\
\hline B3 & $4.55(0.10)$ & $4.40(0.11)$ & 0.154 & 1.01 & 0.312 \\
\hline B4 & $5.00(0.09)$ & $4.99(0.09)$ & 0.014 & 0.109 & 0.913 \\
\hline B5 & $4.60(0.11)$ & $4.44(0.11)$ & 0.161 & 1.007 & 0.315 \\
\hline B6 & $4.14(0.10)$ & $4.40(0.11)$ & -0.258 & -1.702 & 0.089 \\
\hline D1 & $\mathbf{5 . 3 0}(\mathbf{0 . 0 9})$ & $\mathbf{4 . 2 6}(\mathbf{0 . 0 9})$ & $\mathbf{1 . 0 3 9}$ & $\mathbf{7 . 7 6 8}$ & $<\mathbf{0 . 0 0 1}$ \\
\hline D2 & $4.52(0.10)$ & $4.67(0.11)$ & -0.141 & -0.907 & 0.365 \\
\hline D3 & $4.81(0.10)$ & $4.78(0.11)$ & 0.027 & 0.176 & 0.861 \\
\hline D4 & $3.92(0.09)$ & $3.85(0.11)$ & 0.070 & 0.469 & 0.639 \\
\hline D5 & $3.95(0.12)$ & $3.88(0.11)$ & 0.067 & 0.412 & 0.681 \\
\hline D6 & $3.89(0.11)$ & $3.79(0.10)$ & 0.106 & 0.667 & 0.505 \\
\hline D7 & $5.42(0.09)$ & $5.24(0.08)$ & 0.179 & 1.354 & 0.176 \\
\hline D8 & $\mathbf{4 . 6 4}(\mathbf{0 . 1 0})$ & $\mathbf{5 . 2 2}(\mathbf{0 . 0 8})$ & $\mathbf{- 0 . 5 7 6}$ & $\mathbf{- 4 . 3 3 0}$ & $<\mathbf{0 . 0 0 1}$ \\
\hline D9 & $3.85(0.09)$ & $3.76(0.10)$ & 0.085 & 0.601 & 0.548 \\
\hline D10 & $\mathbf{3 . 3 0}(\mathbf{0 . 1 1})$ & $\mathbf{4 . 1 0 ( 0 . 1 0 )}$ & $\mathbf{- 0 . 7 9 9}$ & $\mathbf{- 5 . 2 3 6}$ & $<\mathbf{0 . 0 0 1}$ \\
\hline O1 & $4.14(0.10)$ & $4.15(0.10)$ & -0.007 & -0.045 & 0.964 \\
\hline O2 & $3.88(0.10)$ & $3.77(0.10)$ & 0.110 & 0.763 & 0.446 \\
\hline O3 & $4.60(0.10)$ & $4.48(0.10)$ & 0.114 & 0.794 & 0.428 \\
\hline
\end{tabular}

We also wanted to find out whether responses from public and private schools are different within each country. Thus, we ran analysis to compare the mean differences between responses from public and private schools in each country. Eleven questions had statistically significant responses in China: B1, B2, D3, D4, D5, D6, D9, D10, O1, O2, O3 (pvalue $<=0.05$ ) while in the U.S., four questions demonstrated differences: B2, B5, D5, D6. Tables 4 and 5 present the means, mean difference, t-value, and p-value from each question in China and the U.S. respectively.

H2a-c are mainly supported. The public school students in China agree more with the benefit statements of digital surveillance than the private school students $(\mathrm{B} 1-5.36$ vs. 4.79 , p-value $=0.004 ; \mathrm{B} 2-6.09$ vs. 5.74 , $\mathrm{p}$-value $=0.038)$. The private school students are more concerned about the detrimental effects of digital surveillance than the public school students, demonstrated by their responses on D3, D4, D5, and D6 (D3 - 5.26 vs. 4.30, p-value < 0.001; D4 4.31 vs. 3.37 , p-value $<0.001$; D5 -4.22 vs. 3.53 , p-value $=0.002$; D6 -4.00 vs. 3.57 , p-value $=0.048$ ). The private school students generally disapproved more of digital surveillance than the public school students $(\mathrm{O} 1-3.76$ vs. 4.54 , p-value $<0.001 ; \mathrm{O} 2-4.20$ vs. 3.33 , p-value $<0.001 ; \mathrm{O} 3-4.07$ vs. 4.90 , p-value $<0.001$ ). 
Table 4. China - Public Schools versus Private Schools

\begin{tabular}{|c|c|c|c|c|c|}
\hline Question & Public & Private & $\begin{array}{l}\text { Mean } \\
\text { difference }\end{array}$ & t-value & p-value \\
\hline B1 & $5.36(0.12)$ & $4.79(0.17)$ & 0.568 & 2.909 & 0.004 \\
\hline B2 & $6.09(0.09)$ & $5.74(0.14)$ & -0.196 & 2.084 & 0.038 \\
\hline B3 & $4.37(0.14)$ & $4.42(0.17)$ & 0.154 & -0.188 & 0.851 \\
\hline B4 & $4.99(0.10)$ & $4.98(0.14)$ & 0.014 & 0.051 & 0.960 \\
\hline B5 & $4.52(0.15)$ & $4.36(0.17)$ & 0.161 & 0.701 & 0.484 \\
\hline B6 & $4.38(0.13)$ & $4.41(0.17)$ & -0.258 & -0.109 & 0.913 \\
\hline D1 & $4.29(0.11)$ & $4.23(0.15)$ & 1.039 & 0.301 & 0.763 \\
\hline $\mathrm{D} 2$ & $4.61(0.14)$ & $4.72(0.17)$ & -0.141 & -0.501 & 0.617 \\
\hline D3 & $4.30(0.13)$ & $5.26(0.17)$ & 0.027 & -4.368 & $<0.001$ \\
\hline D4 & $3.37(0.12)$ & $4.31(0.18)$ & 0.070 & -4.284 & $<0.001$ \\
\hline D5 & $3.53(0.12)$ & $4.22(0.17)$ & 0.067 & -3.183 & 0.002 \\
\hline D6 & $3.57(0.13)$ & $4.00(0.16)$ & 0.106 & -1.990 & 0.048 \\
\hline $\mathrm{D} 7$ & $5.09(0.11)$ & $5.38(0.13)$ & 0.179 & -1.622 & 0.106 \\
\hline D8 & $5.13(0.10)$ & $5.31(0.12)$ & -0.576 & -1.040 & 0.300 \\
\hline D9 & $3.36(0.11)$ & $4.16(0.16)$ & 0.085 & -3.942 & $<0.001$ \\
\hline D10 & $3.65(0.11)$ & $4.54(0.17)$ & -0.799 & -4.334 & $<0.001$ \\
\hline O1 & $4.54(0.12)$ & $3.76(0.16)$ & -0.007 & 3.846 & $<0.001$ \\
\hline $\mathrm{O2}$ & $3.33(0.10)$ & $4.20(0.16)$ & 0.110 & -4.507 & $<0.001$ \\
\hline $\mathbf{O 3}$ & $4.90(0.11)$ & $4.07(0.15)$ & 0.114 & 4.202 & $<0.001$ \\
\hline
\end{tabular}

H4a-c are largely supported. The private school students in the U.S. are more aware of the benefits of digital surveillance than the public school students (B2 -6.02 vs. 5.63, p-value $=0.040$; B5 -5.12 vs. 4.44, $\mathrm{p}$-value $=0.008$ ). The public school students were more aware of the detrimental effects of digital surveillance than the private school students (D5 -4.12 vs. 3.39, $\mathrm{p}$-value $=0.008$; D6 -4.07 vs. 3.33, $\mathrm{p}$-value $=0.006$ ). The data showed little difference in their general opinion of digital surveillance (O1-O3).

Table 5. U.S. - Public Schools versus Private Schools

\begin{tabular}{|l|l|l|l|l|l|}
\hline Question & Public & Private & $\begin{array}{l}\text { Mean } \\
\text { difference }\end{array}$ & t-value & p-value \\
\hline B1 & $4.94(0.10)$ & $5.22(0.16)$ & -0.283 & -1.323 & 0.187 \\
\hline B2 & $\mathbf{5 . 6 3 ( 0 . 0 9 )}$ & $\mathbf{6 . 0 2}(\mathbf{0 . 1 5})$ & $\mathbf{- 0 . 3 9 5}$ & $\mathbf{- 2 . 0 7 0}$ & $\mathbf{0 . 0 4 0}$ \\
\hline B3 & $4.54(0.11)$ & $4.57(0.19)$ & -0.029 & -0.126 & 0.900 \\
\hline B4 & $4.96(0.10)$ & $5.12(0.17)$ & -0.161 & -0.766 & 0.445 \\
\hline B5 & $\mathbf{4 . 4 4 ( 0 . 1 2 )}$ & $\mathbf{5 . 1 2}(\mathbf{0 . 2 0})$ & $\mathbf{- 0 . 6 8 4}$ & $\mathbf{- 2 . 6 9 1}$ & $\mathbf{0 . 0 0 8}$ \\
\hline B6 & $4.04(0.12)$ & $4.45(0.19)$ & -0.410 & -1.704 & 0.090 \\
\hline D1 & $5.39(0.10)$ & $5.00(0.19)$ & 0.394 & 1.832 & 0.068 \\
\hline D2 & $4.55(0.12)$ & $4.45(0.20)$ & 0.099 & 0.408 & 0.684 \\
\hline D3 & $4.86(0.12)$ & $4.65(0.20)$ & 0.205 & 0.831 & 0.407 \\
\hline D4 & $3.99(0.10)$ & $3.69(0.19)$ & 0.293 & 1.318 & 0.189 \\
\hline D5 & $\mathbf{4 . 1 2 ( 0 . 1 4 )}$ & $\mathbf{3 . 3 9}(\mathbf{0 . 2 1})$ & $\mathbf{0 . 7 3 5}$ & $\mathbf{2 . 6 5 9}$ & $\mathbf{0 . 0 0 8}$ \\
\hline D6 & $\mathbf{4 . 0 7}(\mathbf{0 . 1 3})$ & $\mathbf{3 . 3 3 ( 0 . 2 0 )}$ & $\mathbf{0 . 7 4 4}$ & $\mathbf{2 . 7 8 1}$ & $\mathbf{0 . 0 0 6}$ \\
\hline D7 & $5.37(0.11)$ & $5.55(0.17)$ & -0.177 & -0.763 & 0.447 \\
\hline D8 & $4.70(0.12)$ & $4.47(0.20)$ & 0.227 & 0.933 & 0.352 \\
\hline D9 & $3.92(0.11)$ & $3.63(0.18)$ & 0.283 & 1.266 & 0.207 \\
\hline D10 & $3.26(0.13)$ & $3.41(0.19)$ & -0.144 & -0.558 & 0.577 \\
\hline O1 & $3.92(0.24)$ & $4.21(0.11)$ & -0.295 & -1.191 & 0.235 \\
\hline O2 & $3.95(0.22)$ & $3.85(0.11)$ & 0.108 & 0.448 & 0.655 \\
\hline O3 & $4.52(0.10)$ & $4.87(0.25)$ & -0.314 & -1.321 & 0.188 \\
\hline
\end{tabular}




\section{Study 2 - Text Analysis}

Many students expressed comments in the survey. In this section, we report what we found from their comments. The major reasons for respondents to support surveillance are: improve security, deter and solve crimes. The issues with digital surveillance the respondents stated are: violate human rights, freedom, privacy, surveillance is not effective, data not secured, government/police corruption, targeting terrorists is ok but not law-abiding citizens. The Chinese students included a few areas their US counterparts did not mention. Chinese students believe digital surveillance is a good idea because it regulates human behavior. Most of them state surveillance in public places is OK, but not in private places. Some do not like the idea of installing surveillance in the classroom, school campus, especially when there are "high caliber students" on campus. One student wrote "our school has over 400 surveillance cameras, haha haha."

Examples of statements supporting digital surveillance are:

"I think they (digital surveillance) are helpful with crimes and solving difficult cases."

"Surveillance can deter shop lifting. It is good to regulate public behavior, as well as preventing certain unexpected events in life."

"Surveillance can regulate people's behavior and solve lots of issues."

"Surveillance should be installed where there is heavy traffic such as store fronts, intersections, banks, and it should be used to safeguard security."

Examples of statements opposing digital surveillance are:

"Digital surveillance severely reduces our rights and freedom."

"Digital surveillance is a bunch of caca. I think it invades privacy."

"I feel as if they don't help at all because it just records the crime. It doesn't stop it from happening at all."

"Privacy cannot be guaranteed. Generally, I don't like being watched."

"Digital surveillance violates individual privacy. When you know you are under surveillance, you would lose your sense of safety."

Examples of "it depends" statements are:

"I believe public surveillance just as anything else in this world can be abused if in the wrong hands."

"It can be a good or bad thing depending on who is in control of it."

"Surveillance devices can only be installed on conditions that privacy will not be violated and with permission."

"Surveillance has some benefits but sometimes it can violate privacy causing some uneasiness. Private personal information like phone numbers obtained by bad people pose a threat and even cause damage."

We listed the number of comments that support, oppose, and depends in Table 6. There are more depends than strictly supporting or opposing comments.

Table 6. Number of Statements by Category

\begin{tabular}{|l|l|l|l|l|l|}
\hline & U.S. & China & $\begin{array}{l}\text { U.S. } \\
\text { Public, } \\
\text { Private }\end{array}$ & $\begin{array}{l}\text { China } \\
\text { Public, } \\
\text { Private }\end{array}$ & Total \\
\hline For & $12(29 \%)$ & $34(30 \%)$ & 5,7 & 22,12 & 46 \\
\hline Against & $11(24 \%)$ & $30(26 \%)$ & 10,1 & 13,17 & 40 \\
\hline Depends & $19(46 \%)$ & $48(42 \%)$ & 17,2 & 19,29 & 67 \\
\hline Total & $41(100 \%)$ & $112(100 \%)$ & 32,10 & 54,58 & 153 \\
\hline
\end{tabular}

Out of the 41 total statements from the US students, 29 percent support digital surveillance, 24 percent oppose, and 46 percent state their views depend on the circumstances. The comments from the Chinese students have similar percentages: 30 percent support, 26 percent oppose, and 42 percent depends. Therefore, the views of students from 
the two countries do not seem to be much different. However, when we compare the public vs. private schools within each country, it is clear that in China more comments from public students are positive and more comments from private schools are negative about digital surveillance. US data is the opposite: more comments from private school students are for, and more from public school students are against digital surveillance.

We also identified the number of comments that listed reasons why the respondents support or oppose digital surveillance. Please see Table 7 for details. One comment may include several reasons, thus, the numbers in Table 7 may not add up to the ones in Table 6. The Chinese students state three more benefits of digital surveillance: regulate public behavior, prevent shoplifting, and anti-corruption. Quite a few include regulating public behavior in their comments. Regarding concerns, Chinese students specifically point out they do not like surveillance on school campuses, surveillance could make people uncomfortable, do not like being surveilled without prior notification, and surveillance data may not be secured, while the US students advocate surveillance should not target religious and racial groups.

Table 7. Number of Statements by Reasons

\begin{tabular}{|l|l|l|}
\hline & $\begin{array}{l}\text { U.S. } \\
\text { Public, private }\end{array}$ & $\begin{array}{l}\text { China } \\
\text { Public, private }\end{array}$ \\
\hline Digital surveillance has benefits: & & \\
\hline Improves security & 4,0 & 12,6 \\
\hline Deter crime & 3,6 & 9,5 \\
\hline Regulate public behavior & & 6,5 \\
\hline Shoplifting & & 1,0 \\
\hline Anti-corruption & & 1,0 \\
\hline & & \\
\hline Digital surveillance raises concerns: & & \\
\hline Violate human rights, freedom, privacy & 9,0 & 18,19 \\
\hline Abusive power, corrupted government & & 0,2 \\
\hline Can be in the wrong hand & 4,1 & 1,2 \\
\hline Not useful, inefficient, excessive use & 2,0 & 3,1 \\
\hline Uncomfortable & & 4,3 \\
\hline at school, private places & 2,0 & 13,17 \\
\hline Excessive use, misuse & 5,0 & 3,1 \\
\hline No prior permission & & 2,1 \\
\hline Religious racial targeting & 1,1 & \\
\hline Collected data not secured & & 6,2 \\
\hline
\end{tabular}

\section{DISCUSSION}

Overall, high school students in both countries thought digital surveillance helps solve criminal cases $($ mean $=5.84)$ and reduce crimes $($ mean $=5.04)$. They also believed data collected from digital surveillance can easily be abused $($ mean $=5.32)$. They generally did not approve of government surveillance $($ mean $=3.15)$. The results seem to indicate teenagers' mixed feelings about surveillance. They struggle for a balance between the pros and cons of surveillance like a scale balance tipping to one end when pros weigh more and to the other when cons weigh heavier. O1 conveys a strong distrust in government conducting the surveillance. O3 seems to confirm the shift, back to the benefits of digital surveillance in general.

We hypothesized the Chinese students would consent more to the benefits of digital surveillance than their counterparts in the U.S. This hypothesis was not supported. The students from two countries seemed to consent equally to the benefits. The hypothesis that US students would be more aware of the detriments of digital surveillance was supported on one account regarding digital surveillance expanding government power (5:30 vs. 4.26, p-value $<$ 0.001). On two accounts (digital surveillance data tend to be misused; digital surveillance inconveniences my daily action.), we found the opposite to be true. In addition, we did not find significant differences on the general opinions 
of digital surveillance (O1-3) between the two groups of students. Digital surveillance is a relatively new phenomenon. People around the world including teenagers in China and the U.S. have been introduced to it about the same time with similar degrees of intensity and prevalence. They may have similar experiences with its impact on society through public media and personal encounters. For example, solving a high profile criminal case with the aid of public surveillance may influence how teenagers view the benefits of surveillance. As China becomes more westernized, people are influenced by the soft power of the West such as media, entertainment, and other culture products. People, especially teenagers, are fast buying into Western ideology and are increasingly aware of individual liberty even when their political rights are limited. Although left-leaning ideologies such socialism and communism are extremely prevalent on the executive level of the Chinese government, suppression of Western thought and democratic ideals is largely unsuccessful in mainland China due to social and political activists in China and other parts of the world and the establishment of virtual private networks. This indicates many Chinese youth are ready to become political moderates, thus explaining the parallel responses to American students.

We found significant differences in responses from public and private school students in China. On general opinions, we found the private school students were less favorable of digital surveillance than the public school students. For example, public school students slightly agree with the statement "I approve of government surveillance" while private school students largely disagree. Public school students thought digital surveillance is a good idea while private school students stayed neutral. On benefits and detriments of digital surveillance, we found public school students agreed more strongly on two accounts of benefits (B1 and B2) while private school students agree more on six accounts of detriments (D3-6, D9-10). Our hypotheses on differences between public and private school students in China are largely supported. We use "largely" because even though there was a trend of differences, the differences were not found on all of the statements. In China, private school students are from affluent families with resources to more readily consume Western products and culture than the general public. Under the influence of Western culture, they are more aware of individual rights, and more suspicious of government behavior. Regarding differences between public and private schools in the U.S., we found public school students tended to be less aware of the benefits but more aware of the detriments than private school students. We didn't see significant differences on the two groups' general opinions of digital surveillance. But again, that might be due to the much smaller sample size from private school students. The US public school students are racially and social- economically diverse. They seem to be more socially liberal towards issues related to government involvement, resulting in support for policies that protect the individual rights of victims of surveillance. Private school students on the other hand, are more homogeneous and conservative, indicating stronger support for activities bolstering national security and specifically the War on Terror.

In the survey comments section, the Chinese students specified a few more benefits and detriments. The additional benefits are: regulate human behavior, prevent shoplifting, can be a tool of anti-corruption. The detriments are: data not secured, abusive power, digital surveillance makes people uncomfortable. The one area US students commented where Chinese students did not, was "digital surveillance targets certain religious or racial groups." Proper behavior in the public is highly emphasized and valued by Chinese families and schools. It is an important success indicator of a teenager's upbringing and education. Since it is emphasized throughout every stage of growth and education, it is natural for the Chinese respondents to mention this numerous times. Regarding race and religion in China, diversity is almost non-existent in most areas, while in the U.S, race and religious differences are woven everywhere into the American societal fabric. That is why US teenagers identified race and religion in their comments.

This research has three implications. First, teenagers in general have slightly positive attitudes towards surveillance, recognizing its pros such as solving crimes and improving security. However, the distrust in the government's role in digital surveillance is evident. Therefore, decentralizing surveillance, i.e. giving the surveilling power to local agencies and institutions, may achieve better results. Second, surveilling agencies need to devote time and resources to safeguard data obtained through digital surveillance. Periodic public hearings about how data is secured and used could reduce concerns, anxiety, and fear. Third, national boundaries seem to have little impact on teenagers' attitude towards digital surveillance. However, within the country, social-economic status and ideologies seem to play a bigger role in their perception of surveillance. The world is getting smaller, but the differences within a country seem to grow wider. Public administration and safety professionals need to be aware of this when they develop policies and institute surveillance in the public space. 


\section{Issues in Information Systems}

Volume 18, Issue 1, pp. 98-108, 2017

\section{LIMITATIONS AND FUTURE RESEARCH}

This research has several limitations which lead to future research. We collected data from four schools located in two countries, and the responses from US private schools are particularly small. Future research should reach out to more schools in both countries. It will be also nice to survey high school students in countries other than the U.S. or China. Furthermore, identifying theories underpinning this line of research will be helpful as well.

\section{REFERENCES}

Ball, K., \& Snider, L. (2013). The surveillance-industrial complex: A political economy of surveillance. Routledge.

CBS News (2013). FBI Director Suggests NSA Surveillance Might Have Stopped 9/11. Available http://www.cbsnews.com/videos/fbi-director-suggests-nsa-surveillance-might-have-stopped-911/.

Digital. Merriam-Webster Dictionary. https://www.merriam-webster.com/dictionary/digital

Electronic Frontier Foundation (EFF) (2017). NSA Spying on Americans. Last accessed on 4/19/2017 https://www.eff.org/nsa-spying.

Expat Arrivals (2017). Education and Schools in China. Last accessed on 4/19/2017 http://www.expatarrivals.com/china/education-and-schools-in-china.

Globe Scan (2014). BBC World Service Poll. Available http://www.globescan.com/images/images/pressreleases/2014-BBCFreedom/BBC_GlobeScan_Freedom_Release_Final_March25.pdf.

Guardian (2015). Digital Surveillance 'Worse than Orwell', Says New UN Privacy Chief. Available https://www.theguardian.com/world/2015/aug/24/we-need-geneva-convention-for-the-internet-says-newun-privacy-chief.

Lyon, D. (2007). Surveillance studies: An overview. Polity Press.

Madden, M. \& Rainie, L. (2015b). Americans' Attitudes about Privacy, Security and Surveillance. Available http://www.pewinternet.org/2015/05/20/americans-attitudes-about-privacy-security-and-surveillance/.

Markantonatou, M. (2007). The Intensification of Surveillance: Crime, Terrorism and Warfare in the Information Age [Book Review]. Australian and New Zealand Journal of Criminology, 40(2), 245-247.

Martin, A. K., Van Brakel, R. E., \& Bernhard, D. J. (2009). Understanding resistance to digital surveillance: Towards a multi-disciplinary, multi-actor framework. Surveillance \& Society, 6(3), 213-232.

Newport, Frank (2013). Americans Disapprove of Government Surveillance Programs. Available http://www.gallup.com/poll/163043/americans-disapprove-government-surveillance-programs.aspx.

NPR (2013). In China, Beware: A Camera May Be Watching You. Available http://www.npr.org/2013/01/29/170469038/in-china-beware-a-camera-may-be-watching-you.

Rainie, L. \& Madden, M. (2015a). Americans' Views on Government Surveillance Programs. Available http://www.pewinternet.org/2015/03/16/americans-views-on-government-surveillance-programs/. 